\title{
Subsurface void detection under the road surface using ground penetrating radar (GPR), a case study in the Bangkok metropolitan area, Thailand
}

Thanop Thitimakorn ${ }^{1 *}$, Natamon Kampananon ${ }^{2}$, Napassapong Jongjaiwanichkit ${ }^{2}$ and Sasikan Kupongsak ${ }^{3}$

*Correspondence:

thanop.t@chula.ac.th

1 Department of Geology,

Faculty of Science,

Chulalongkorn University, Bangkok 10330, Thailand

Full list of author information

is available at the end of the article

\begin{abstract}
Background: There have been several recent reports of collapsed roads at the various locations throughout the Bangkok metropolitan area. Most of the problems are caused by improper construction of utility networks and poor rehabilitation work. Ground penetrating radar (GPR) technique was selected to investigate the potential presence of subsurface voids under the road surface. In geotechnical and structural applications, GPR is an excellent tool for being able to image steel reinforcing bars, voids and tendon ducts in concrete structures and, more relevantly to this study, voids beneath concrete roads.
\end{abstract}

Objectives: The objective of this study was to survey the area for potential voids that might exist under the road surface using ground penetrating radar technique.

Methods: The GPR survey campaign was divided into two stages, which were the preliminary and detailed surveys. The objective of the preliminary survey was to quickly survey the area for potential voids that might exist under the road surface and subsequently a more detailed survey of those areas was performed to confirm the existence and determined the lateral and vertical extension of the potential void(s) identified in the preliminary GPR survey. The GPR data were collected with $400 \mathrm{MHz}$ antenna mounted on a survey cart.

Results: Several void-like anomalies were detected from the GPR data and these selected anomalies were drilled to confirm the existence of a void. However, some GPR anomalies were found not to be voids, and mostly came from areas of past road maintenance or manholes with a hidden cover (asphaltic concrete overlay). One example of a large void under the road surface was detected in this study, being clearly seen in the GPR data and then confirmed by drilling.

Conclusion: The GPR method was successfully used for void detection under a main road in Bangkok city. In this study the $400 \mathrm{MHz}$ ground-coupled antenna was used to image potential subsurface voids and these were then confirmed (or not) by drilling boreholes in that area through the road surface. In the example shown in this report as a case study, the identified void was approximately $4 \mathrm{~m}$ long, $2 \mathrm{~m}$ wide and $1.5 \mathrm{~m}$ deep. As a result of its discovery it was subsequently treated by backfilling and a new road surface was then constructed.

Keywords: GPR, Void, Pavement

\section{望 Springer}

(c) 2016 Thitimakorn et al. This article is distributed under the terms of the Creative Commons Attribution 4.0 International License (http://creativecommons.org/licenses/by/4.0/), which permits unrestricted use, distribution, and reproduction in any medium, provided you give appropriate credit to the original author(s) and the source, provide a link to the Creative Commons license, and indicate if changes were made. 


\section{Background}

There have been several recent reports of collapsed roads at the various locations throughout the Bangkok metropolitan area (capital city of Thailand). Most of the problems are caused by improper construction of utility networks and poor rehabilitation work. Leakage of water from the underground pipe lines and storm water are the most important problems that cause the loosening of foundation material around and below the road surface and their subsequent removal causing the further develop into large voids. One such recent example, which was located on the intersection of Rama IV and Silom roads (two main and busy roads in central Bangkok). The void caused the road surface to collapse leaving a relatively deep hole of nearly $5 \mathrm{~m}$ in diameter and $2 \mathrm{~m}$ in depth in the road surface. After investigation it was concluded that the cause of this void was due to the improper construction of utility networks that caused leakage from an old water pipe underneath. Indeed, the leakage of water from underground pipe lines and storm water are the most important causes of loose substratum and foundation material under the road surface, and these can then further develop into large voids. Because of the large void that recently occurred on Rama IV Road, the Bangkok Authority Administration (BAA) decided to further investigate the entire section of Rama IV road that overlies the section of the MRT (underground train) line in order to locate any other voids under or in the immediate vicinity of the road and pavement.

However, the closing of Rama IV road to traffic for sufficient time to perform a standard drilling and borehole based survey for subsurface voids was impractical and so to accomplish this survey ground penetrating radar (GPR) was selected to preliminarily investigate the potential presence of subsurface voids in both the outbound and inbound lanes of the section of Rama IV road above the MRT line. The nondestructive GPR technique monitors the return back to the ground surface of reflected and refracted electromagnetic waves (EMWs) that were sent into the subsurface. Thus, subsurface profiling with GPR is similar in principal to that of seismic exploration except that GPR utilizes EMWs instead of sound waves. As the EMW is transmitted into the subsurface, the degree of reflection and refraction depends on the discontinuities in the subsurface [13]. In contrast to seismic analysis, these discontinuities are the electrical properties of the substratum (mainly the relative dielectric permittivity) and not elastic parameter discontinuities. The principles of GPR and its limitations have been discussed extensively before [4-6] and readers wanting more information are directed to these reviews. In geotechnical and structural applications, GPR is an excellent tool for being able to image steel reinforcing bars [7-10], voids and tendon ducts in concrete structures [11] and, more relevantly to this study, voids beneath concrete roads [12].

The depth that can be investigated by GPR is related to the antenna frequencies. The lower the frequency, the deeper the radar wave penetrates. Both low and high antenna frequencies have different advantages and disadvantages. For shallow surveying, low frequency antenna of approximately $100 \mathrm{MHz}$ are appropriate to acquire data from less than $2 \mathrm{~m}$ depth to about $15 \mathrm{~m}$ depth with satisfactory resolution. At a higher frequency $(>400 \mathrm{MHz}$ ) the depth of penetration is limited to $<2 \mathrm{~m}$ but the resolution is quite remarkable [13]. The size of high frequency antennas are relatively small and can be shielded from unwanted electromagnetic energy, whereas it is impractical to shield lower frequency antennas due to their larger dimensions. Although the unshielded GPR 
system is more difficult to work with, it still has advantages over the shielded system in collecting data for velocity analysis or conducting a common mid-point survey (a standard practice for stacking reflection data in the field).

\section{GPR data acquisition}

The GPR survey campaign was divided into two stages, which were the preliminary and detailed surveys. The objective of the preliminary survey was to quickly survey the area for potential voids that might exist under the road surface and subsequently a more detailed survey of those areas was performed to confirm the existence and determine the lateral and vertical extension of the potential void(s) identified in the preliminary GPR survey.

\section{Preliminary survey}

In the preliminary survey, GPR data were collected along a section of Rama IV road in the Bangkok area (Fig. 1) with a $400 \mathrm{MHz}$ antenna and GSSI SIR20 mounted on the survey cart. The sampling interval was 512 sample/scan and time range was 50 ns. Figure 2 shows the SIR20 GPR unit and the setup of $400 \mathrm{MHz}$ antennas. The GPR data were acquired with 1 line of $185 \mathrm{~m}$ length in the inbound direction (Fig. 2). This survey line was planned after visual inspection of Rama IV Road and subsequent selection of the area suspected of containing voids underneath the road surface. After the GPR data were processed and interpreted, the void-like anomalies were marked on the GPR sections. The GPR data of the first stage is shown in Fig. 3.

From the GPR data of Fig. 3, there were two void-like anomalies found in the data. The first anomaly was located at between $5-8 \mathrm{~m}$ of the survey line, while the second appeared at 125-128 $\mathrm{m}$. The first anomaly showed a chaotic pattern in the GPR signal

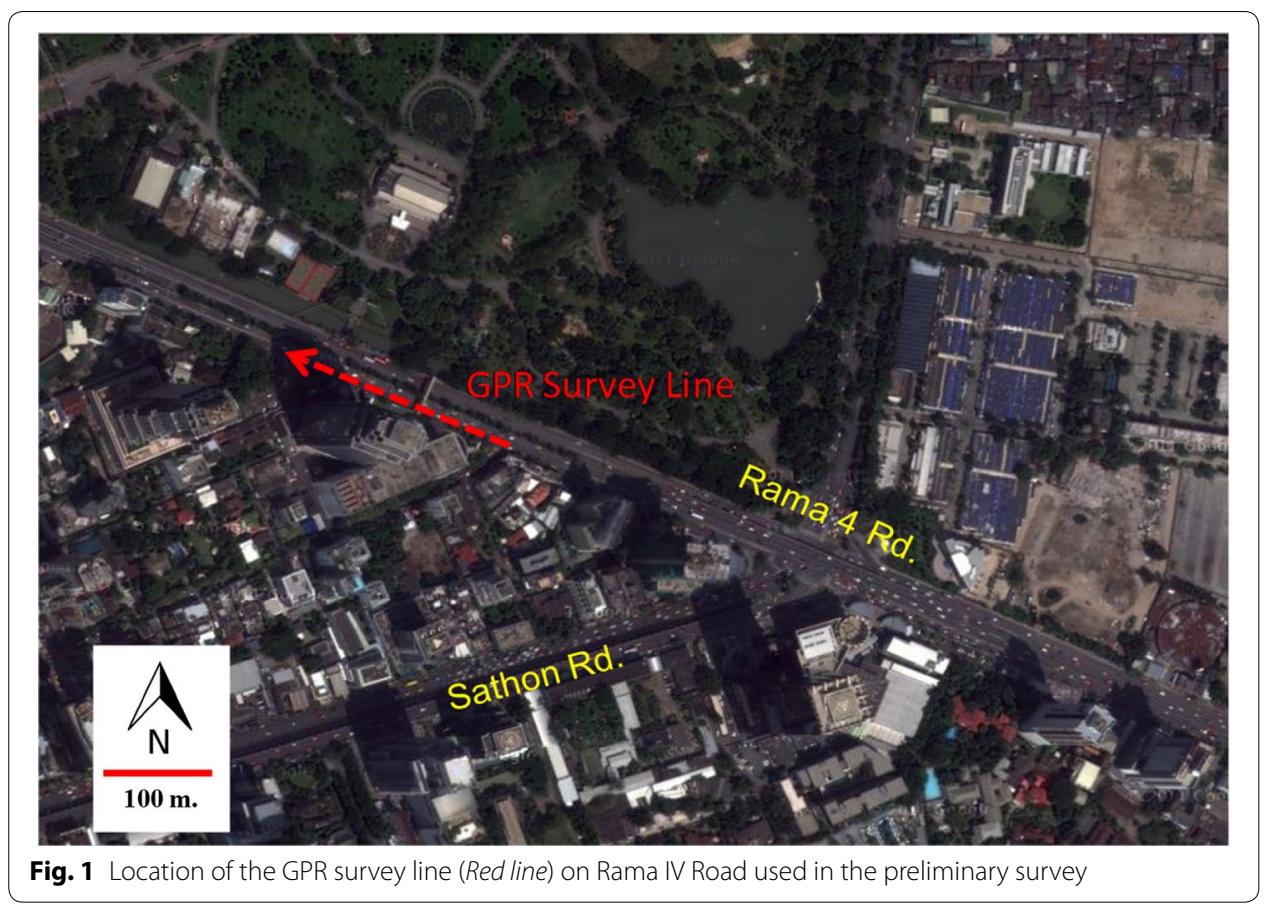




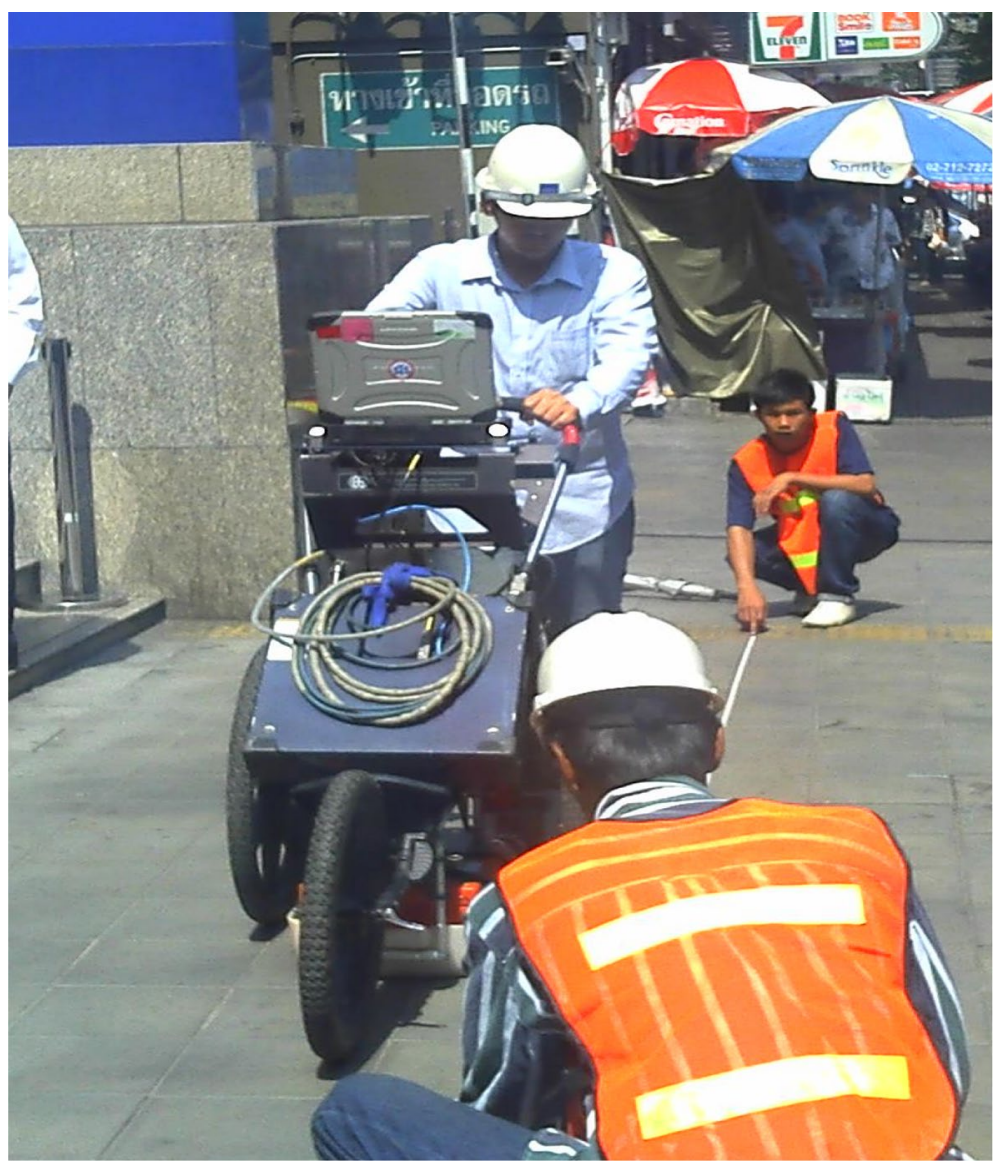

Fig. 2 GPR instruments and the survey cart used during the GPR data collection in the Bangkok area

and appeared right beneath the existing road surface slab and was 3-4 $\mathrm{m}$ wide. The bottom of this anomaly was at about $20 \mathrm{~ns}$. The second anomaly showed a hyperbolic shaped GPR signal diffraction and black-white-black phase reversal. The top of the anomaly was at $25 \mathrm{~ns}$. This anomaly may be a small void located in the sub-grade layer.

However, there were many other signals in the GPR pattern that originated from different objects and features. These features include manholes, utility pipe lines and areas of previous road maintenance. The manhole signal was easy to indentify because its signal starts from the top and continues down to the bottom of the GPR section. The signal from utility pipe lines could also be identified from their hyperbolic shape. The previous maintenance areas can be indentified from historical records and observation of the road (and surrounding pavement area) surface.

\section{Detailed GPR surveys}

In the second stage some of these void-like anomalies were selected for drilling in order to confirm whether the potential voids identified by the preliminary GPR survey actually were existent voids under the road. Before the drilling was started, a more detailed GPR survey was performed at each selected location to determine the vertical and lateral extent of the void-like anomaly. The first anomaly in the preliminary survey line was initially selected because the size and shape of the GPR signal showed a very clear void 


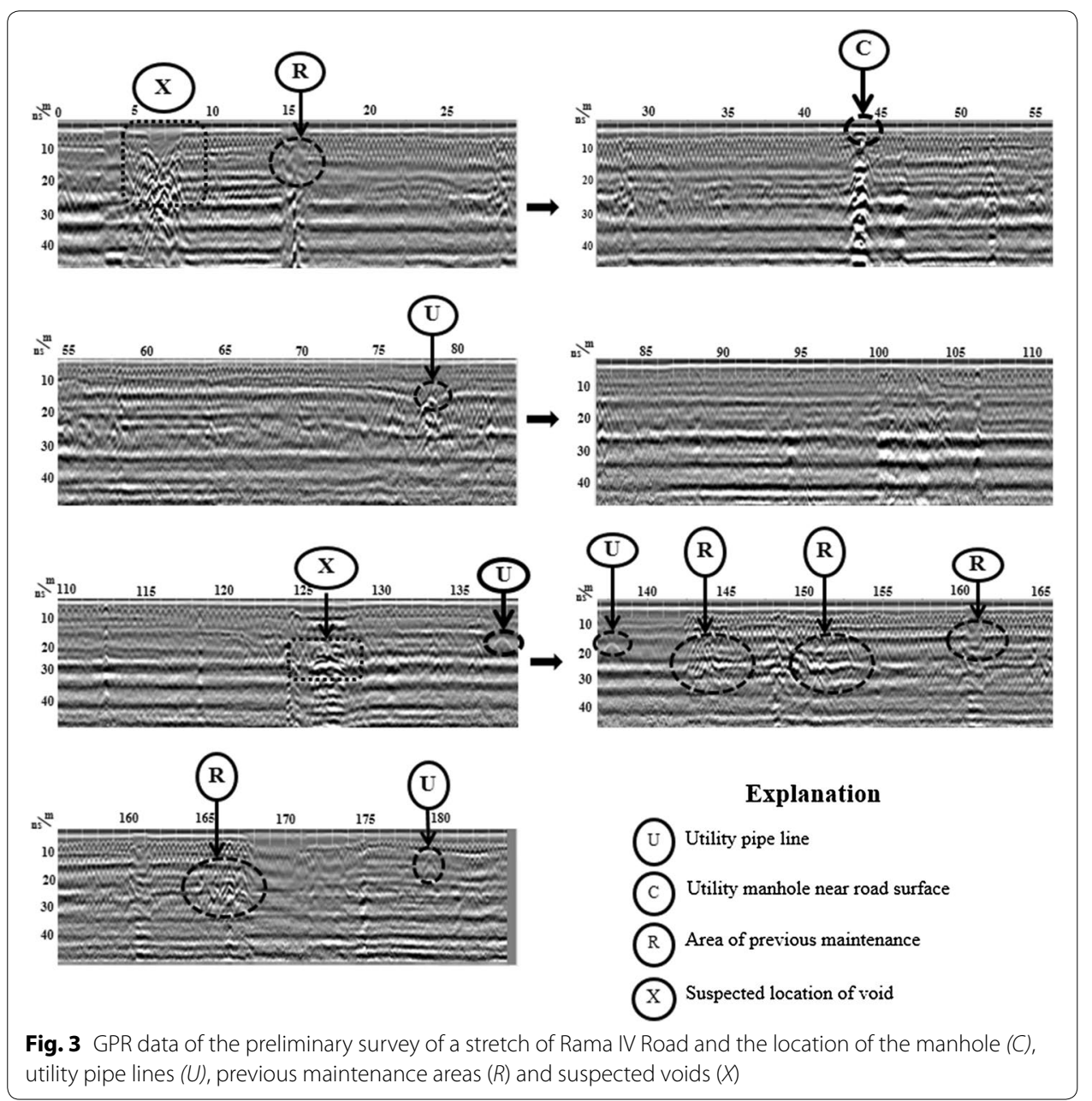

signal and the result of this void is represented here as an example case study. The location of the more detailed survey area and GPR lines used for this surveying this potential void are shown in Fig. 4. As in the preliminary survey, the GPR data were acquired using a $400 \mathrm{MHz}$ antenna mounted on the survey cart and the then processed with position correction, one-dimensional filtering and background removal.

Figure 5 shows the obtained GPR data from the seven survey lines. All the GPR data clearly showed the layer interfaces of the road structures and substratum, plus several signals from utilities were also observed. The void-like anomaly can be seen in the data from survey lines 1-3 at a distance from 13-18 $\mathrm{m}$ from the start of each survey line. The depth of this anomaly was nearly $1 \mathrm{~m}$ and appeared to start right beneath the concrete slab of the road surface.

\section{Drilling results}

To evaluate the actual existence of the potential voids under the road mapped by the GPR analyses, some of the anomalies, including the one reported here, were selected for drilling to confirm the presence of the void. 

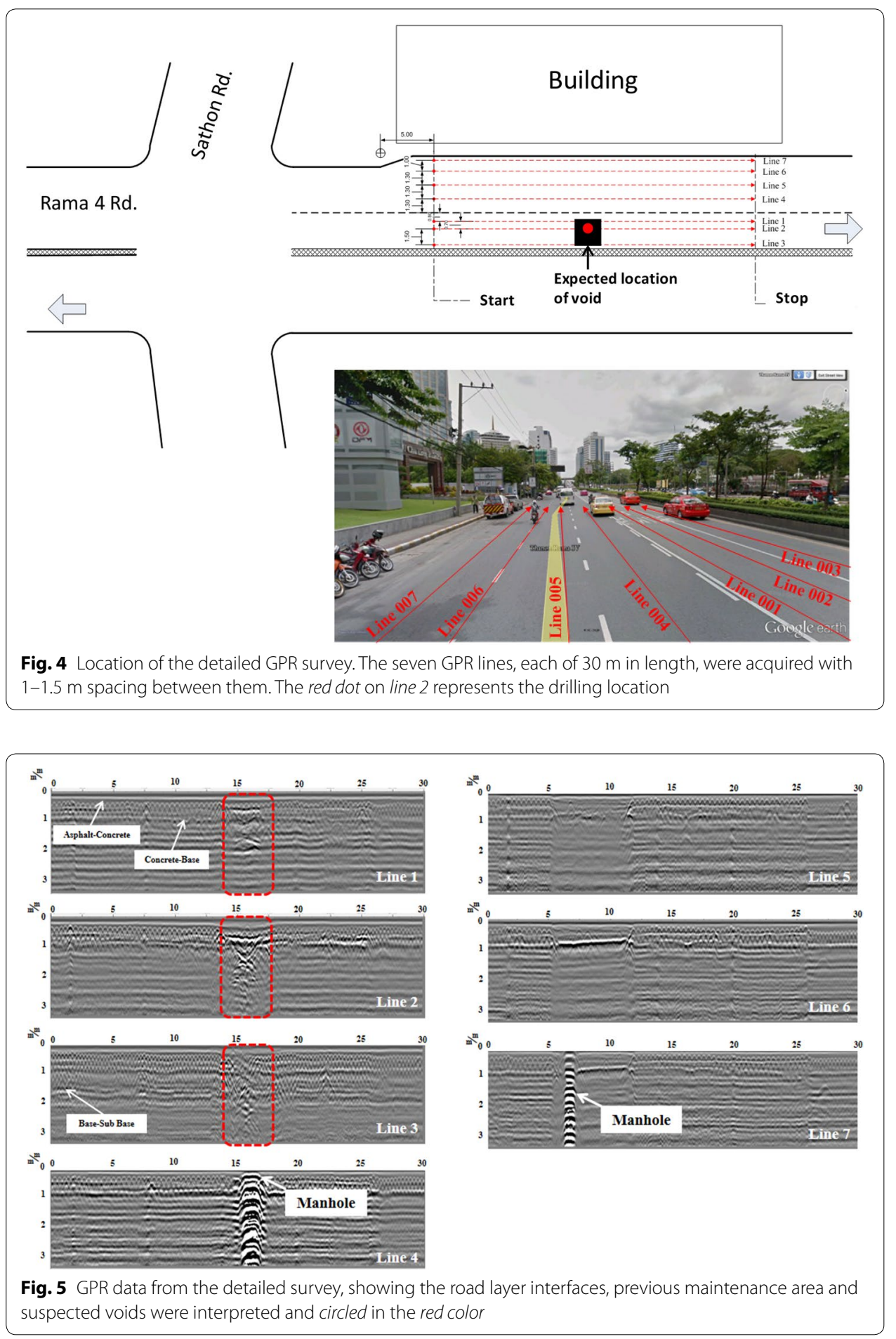

Figure 6 shows the drilling activities performed during the nighttime to avoid closing the road to busy daytime traffic. After each drilling a borehole scope was lowered into the hole to observe and photograph inside it. An example of a picture taken inside a hole at this test site is shown in Fig. $6 \mathrm{~d}$, where the contact area between the concrete 
slab of the road surface and the clear void was evident. Thus, the drilling confirmed that there was a void right under the road surface slab and the depth of this void was $0.76 \mathrm{~m}$. Figure 7 shows the GPR data for this void correlated with the drilling result. Based on the drilling, the asphalt layer ( $0.23 \mathrm{~m}$ thick) was overlaid on the concrete slab (0.27 $\mathrm{m}$ thick) to form the road surface and the rebar reflection was clearly seen in the data. However, some drop off in the concrete slab over the void could be observed at the rebar layer. At the interface between the road concrete slab and the void, the GPR signal showed a pattern of black-white-black phases, which indicated the concrete to air interface.

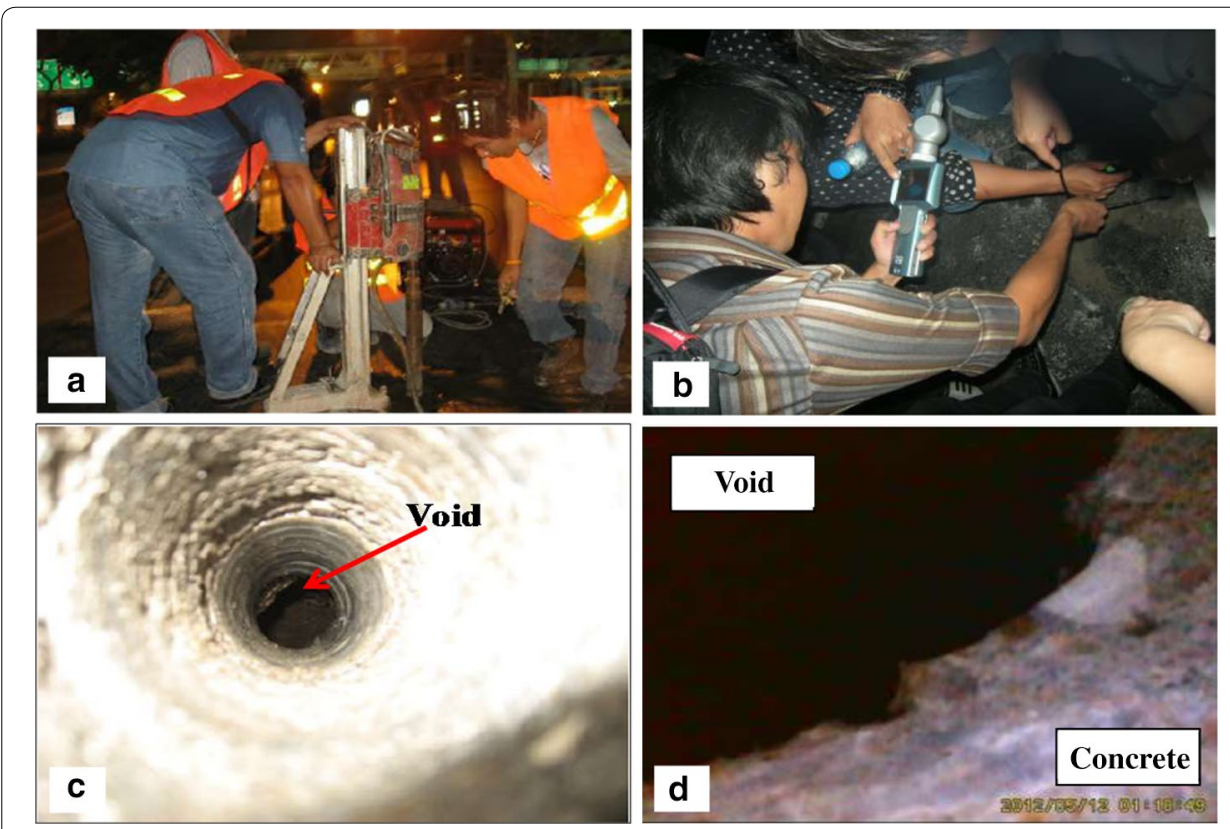

Fig. 6 a Drilling activities over the preselected void target, $\mathbf{b}$ a borehole scope was used to observe inside the drilled hole, $\mathbf{c}$ a representative picture taken inside the hole revealing the void and $\mathbf{d}$ the contact between the concrete road slab and the void

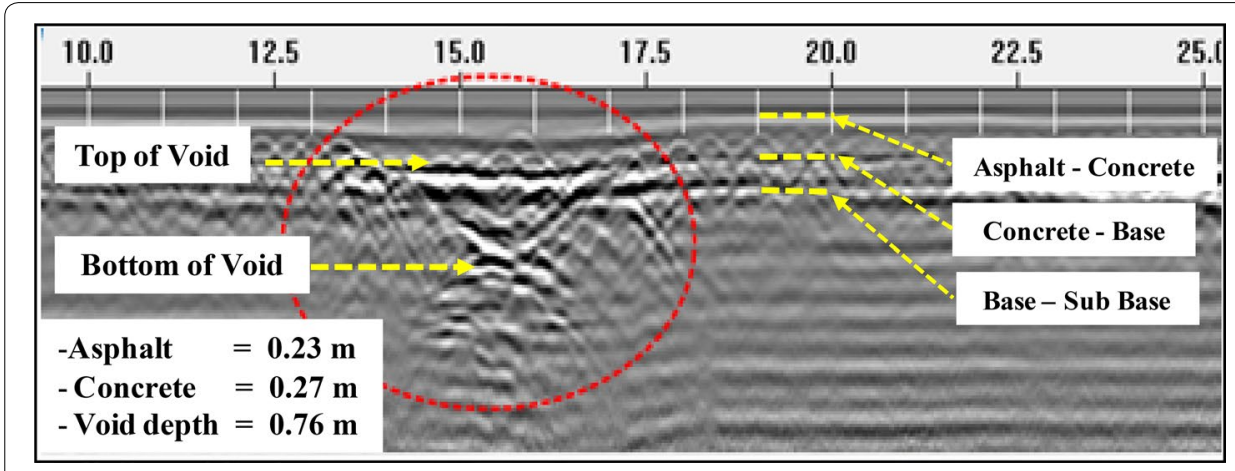

Fig. 7 GPR section of line 3 over the void annotated with the borehole results. The void depth is nearly $0.76 \mathrm{~m}$ and it is right beneath the road concrete slab. The concrete slab shows a drop of the rebar but does not show any sign of depression over the upper road surface that is overlain by the $0.23 \mathrm{~m}$ thick asphaltic layer 


\section{Conclusion}

The GPR method was successfully used for void detection under a main road in Bangkok city. In this study the $400 \mathrm{MHz}$ ground-coupled antenna was used to image potential subsurface voids and these were then confirmed (or not) by drilling boreholes in that area through the road surface. In the example shown in this report as a case study, the identified void was approximately $4 \mathrm{~m}$ long, $2 \mathrm{~m}$ wide and $1.5 \mathrm{~m}$ deep. As a result of its discovery it was subsequently treated by backfilling and a new road surface was then constructed. From this case study, GPR was seen to provide an effective nondestructive tool for subsurface imaging to assess the risk of harmful events. However, GPR surveys cannot be used alone and it does not totally replace the need for boreholes and core samples, but it does help in reducing the number of such boreholes and hence the survey time, cost and inconvenience to more logistically feasible levels for busy main roads.

From the GPR images it was possible to identify the main subsurface features at different depths and locations. We, therefore, demonstrated the success of applying the GPR method to investigate voids under roads or pavements in urban areas. This demonstration will also benefit BMA staff in applying the GPR technology to investigate further subsurface voids in other area around the Bangkok City. They can also include GPR surveying in their geotechnical investigation routine for planning and maintaining the road in the city.

\section{Authors' contributions}

TT carried out the GPR data processing and interpretation and drafted the manuscript. NK and NJ supervised the data acquisitions and reviewed the manuscript. SK helped in conducting the GPR data processing and reviewing the manuscript. All authors read and approved the final manuscript.

\section{Author details}

${ }^{1}$ Department of Geology, Faculty of Science, Chulalongkorn University, Bangkok 10330, Thailand. ${ }^{2}$ STS Engineering Consultants Co Ltd, 196/10-12 Soi Pradipat 14, Pradipat Road, Samsennai, Phayathai, Bangkok 10400, Thailand. ${ }^{3}$ Department of Food Technology, Faculty of Science, Chulalongkorn University, Bangkok 10330, Thailand.

\section{Acknowledgements}

The authors thank STS Engineering Consultants Company Limited for their precious collaboration in giving them access to the geotechnical data for the site under study. Special thank also goes to the Analysis and Research Division, Department of Public Works, Bangkok Metropolitan Administration for allowing the use of the GPR data.

\section{Competing interests}

The authors declare that they have no competing interests.

Received: 27 October 2015 Accepted: 10 February 2016

Published online: 22 February 2016

References

1. Davis JL, Annan AP (1989) Ground penetrating radar for high resolution mapping of soil and rock stratigraphy. Geophys Prospect 37:531-551

2. Fisher E, McMechan GA, Annan AP, Cosway SW (1992) Examples of reverse-time migration of single-channel, ground penetrating radar profiles. Geophysics 57:577-586

3. Neal A (2004) Ground-penetrating radar and its use in sedimentology: principles, problems and progress. Earth Sci Rev 66:261-330

4. Basson U (2000) Imaging of active fault zone in the dead sea rift: Evrona Fault Zone as a case study. Thesis submitted for the degree of Ph.D., Tel-Aviv University, p 196

5. Daniels DJ, Gunton DJ, Scott HF (1988) Introduction to subsurface radar. IEEE Proc Commun Radar Signal Process 35(4):277-392

6. Giang NV (2000) Possibility of the ground penetrating radar application for geotechnical and environment investigation in Vietnam. J Geol 257:3-4

7. Chang CW, Lin CH, Lien HS (2009) Measurement radius of reinforcing steel bar in concrete using digital image GPR. Constr Build Mater 23(2):1057-1063

8. Hugenschmidt J, Kalogeropoulos A (2009) The inspection of retaining walls using GPR. J Appl Geophys 67(4):335-344

9. Hugenschmidt J (2002) Concrete bridge inspection with a mobile GPR system. Constr Build Mater 16:147-154 
10. De Souza $T$ (2005) Ground penetrating radar as an alternative to radiography. Insight 47(7):414-415

11. Maierhofer C (2003) Nondestructive evaluation of concrete infrastructure with ground penetrating radar. J Mater Civil Eng 15(3):287-297

12. Chen $\mathrm{DH}$, Scullion T (2008) Detecting subsurface voids using ground-coupled penetrating radar. Geotech Test J 31(3):217-224

13. Jeng Y, Chen C (2012) Subsurface GPR imaging of a potential collapse area in urban environments. Eng Geol 147:57-67

Submit your manuscript to a SpringerOpen ${ }^{\circ}$ journal and benefit from:

- Convenient online submission

- Rigorous peer review

- Immediate publication on acceptance

- Open access: articles freely available online

- High visibility within the field

- Retaining the copyright to your article 